\title{
STATISTICAL LITERACY AND QUANTITATIVE REASONING: RETHINKING THE CURRICULUM
}

\author{
Gail Burrill \\ Michigan State University \\ burrill@msu.edu
}

\begin{abstract}
The importance of statistical literacy/quantitative reasoning has been highlighted for decades; today the need is even more compelling with data science emerging as foundational in many disciplines. Educated students should understand how to make decisions in the presence of uncertainty and how to interpret quantitative information presented to them in the course of their professional and personal activities. Too often, however, students have limited experience in thinking and reasoning based on real data. This paper explores how ideas from data science interface with notions of statistical literacy/quantitative reasoning, considers foundational concepts necessary to enable students to engage with real data sets in the learning process, and identifies potential curricular elements that are important for all students from these perspectives.
\end{abstract}

\section{INTRODUCTION}

Researchers have highlighted the importance of statistical literacy/quantitative reasoning for decades, but today with "big data", data science, and alternate truths, the need is even more compelling. Today's (and tomorrow's) students live in a world shaped by data. Some will find themselves generating data to answer questions or to investigate situations, but most will function as consumers, given data from which to make decisions or the results of data investigations by others (Gal, 2002). Some will be motivated by curiosity to learn about data in their world (Garber, 2019). Too often, however, the focus of what is taught at the school level is on measures of center and making plots while the focus in college statistical courses is on procedures and tests. Such courses, typically lecture with no active learning or simulation approaches to inference (Lovett \& Lee, 2018), leave students with limited ability to think and reason statistically.

As data is increasingly part of $21^{\text {st }}$ century liberal arts, the question for educators becomes, what does every educated citizen need to know to be "data literate"? Some researchers argue that the answer is probabilistic and statistical literacy (e.g., Gal. 2002). Garber (2019) describes four key principles related to data science necessary for informed decision making: 1) recognizing probabilistic thinking as a framework for understanding uncertainty; 2) understanding the relationship between the sample and the relevant population; 3) recognizing the implications of false positives and negatives; 4) understanding basic inference and the distinction between association and causation. DeVeaux (2019) promotes collaborative projects, where students experience data wrangling, visualize and summarize data, model and simulate deterministic and probabilistic situations, and communicate results in writing, orally and graphically. The International Data Science in Schools Project (IDSSP, 2019) suggests that data science involves behaviors such as problem elicitation and formulation, where students learn to acquire and explore data to understand the world around them, develop a critical (scientific) approach to assessing what they hear and read in the media about data-based assertions, and develop familiarity with computational environments to assist them in exploration, visualization, calculation and presentation.

This paper explores how these ideas interface with earlier notions of statistical literacy and quantitative reasoning, what curricular elements are important for all educated people from these perspectives, and what is necessary to enable learners to engage with real data sets in the learning process. The focus is not on a data science course but on what might constitute a statistical literacy/quantitative reasoning course as a precursor to more formal work in data science.

\section{A FRAMEWORK}

From a simplistic perspective quantitative literacy might imply a "basic competence in mathematics, a basic understanding of numbers and figures" while statistical literacy is the ability to "tell the story present in the numbers" (Australian Bureau of Statistics, 2009). From a curricular perspective in today's world, it seems reasonable to integrate ideas from these two areas, statistical 
literacy and quantitative reasoning, with ideas from data science, which relies on processes and systems to derive information or insights from data. Catalyzing Change (NCTM, 2018) describes quantitative literacy in terms of six abilities as indicated in the first six bullets below (based on Steen, 1997). As noted, these align with important competencies in statistical literacy and data science. Adding two abilities relevant in all three areas gives a framework for thinking about curricula that engage students in reasoning from data. Students should have the ability to

- locate data and assess its validity (Gal, 2002; DeVeaux, 2017)

- use estimation and scale to place quantities in context (Gal, 2000)

- understand numbers as used in everyday discussions (Gal, 2002)

- create and interpret visual representations of data (Gal, 2002)

- understand different ways variables might be linked and recognize the difference between association and causation (Garber, 2019)

- generate and apply probabilistic thinking to decision making, and understand the limitations of such reasoning (Gal, 2002; Garber, 2019)

- consider claims and evidence supporting claims based on reasoning from and about samples (Gal, 2002, Garber, 2019; IDSSP, Steen 2001)

- communicate statistical information with a level of understanding (Gal, 2002; DeVeaux, 2019; Steen, 2001)

The following sections consider several of these abilities with examples of tasks that provide a basis for considering what is important in students' learning.

\section{LOCATE DATA AND ASSESS ITS VALIDITY}

Collecting and managing data - data wrangling- to answer a question of interest is a key element in both statistical literacy (Gal, 2002) and data science (IDSSP, 2019). Textbooks often use small artificial data sets where students are not really expected to interact with the data. To make mathematics and statistics relevant, students can access data from a source such as Census at School $(\mathrm{CaS})$, with over 30 variables on school students by downloading samples of sizes that can vary from 25 to 500. They will have to make decisions about appropriate "data moves" as they encounter missing data and data that do not seem to make sense. Is the student who sent 500 text messages a day an outlier? How about the one who sends 300 a day?

Data from $\mathrm{CaS}$ gives students the opportunity to think about measurements in contextual situations, for example the length of index fingers in $\mathrm{mm}$ for a sample of $11^{\text {th }}$ graders. Several elementary preservice students created dot plots for lengths ranging from $3 \mathrm{~mm}$ to $148 \mathrm{~mm}$ with a small cluster between $3 \mathrm{~mm}$ and $20 \mathrm{~mm}$ and a larger cluster from $62 \mathrm{~mm}$ to $73 \mathrm{~mm}$. The students did not question the disparity in the units (Burrill, 2018). Becoming familiar with units of measurement is part of most school curricula (National Governors Association (NGA), 2010), but actually working with data where units matter is rarely done in mathematics classrooms.

Consider another example of attending to the data in the context of the question, "Are women's earnings catching up to men's?" (See Math Nspired Modeling at educaton.ti.com.) The data can appear in different forms, for example as median incomes for fulltime workers in general, for those over the age of 25, or for year-round workers 15 years old and over; some of the data includes civilians only; some includes self-employed workers; others are for wage and salary workers only. The numbers are reported in terms of yearly income, weekly income, hourly income, earnings ratios, and wage gaps, and could be in original dollars or converted to a common scale. Once they have standardized data, students typically use a variety of approaches to compare the incomes, for example, investigating men's and women's income over time, the ratio of men's income to women's, the difference between men's and women's incomes over time. As an extension, students consider when the salaries might be equal, leading to questions about assumptions and exploring different models (e.g., Will the "me too" movement change the trend?).

\section{ESTIMATION AND SCALE}

Numbers are often used to rank products or people, e.g., ranking computers, airlines, movies, or restaurants. This example is drawn from the American context of football, chosen because it involves several variables and the need to reconcile different units. The quarterback can pass the ball 
to other players downfield in an attempt to reach the goal or can hand the ball to a teammate who attempts to run to the goal. The question: who in the history of the National Football League (NFL) is the "best" passing quarterback? The measures commonly collected for passing are easily accessed for a player at career stats (nfl.com) and include number of touchdowns, number of interceptions, number of passing attempts, number of completions, and yards gained (Table 1).

Table 1 Example of data related to passing for National Football League quarterbacks

\begin{tabular}{|l|l|l|l|l|l|} 
& Touchdowns & Pass completion & Yards gained & Attempts & Interceptions \\
\hline *Tom Brady & 512 & 5967 & 70138 & 9318 & 169 \\
\hline *Drew Brees & 519 & 6559 & 74111 & 9744 & 233 \\
\hline Otto Graham & 174 & 1464 & 23584 & 2626 & 135 \\
\hline *Jameis Winston & 83 & 1127 & 13947 & 1839 & 57 \\
\hline
\end{tabular}

*active through the 2019 season

Students notice the disparity in the magnitude of the numbers and realize that the number of years played affects the statistics (Winston has played five seasons, Brady 20). They should recognize that units matter - the number of yards is large and can overwhelm all of the other numbers. One strategy to address these issues is to identify the "best" per attempt in each category and scale the others in terms of that value. In one list of top-rated quarterbacks over the history of the game, Graham (active 1946-1955) has the most touchdowns and interceptions per attempt; Brees has the largest number of passing completions per attempt. Scaling each of the values in proportion to Graham and Brees produces unitless umbers that can be weighted or combined directly (Table 2). (The NFL has a formula for computing the ratings, which allows students to compare their strategies and results with those of the NFL.)

Table 2

\begin{tabular}{|l|l|l|l|l|} 
& $\begin{array}{l}\text { Touchdowns per } \\
\text { attempt/0.066 }\end{array}$ & $\begin{array}{l}\text { Interceptions per } \\
\text { attempt/0.0514 }\end{array}$ & $\begin{array}{l}\text { Passing completions } \\
\text { per attempt/0.664 }\end{array}$ & $\begin{array}{l}\text { Yards gained per } \\
\text { attempt/8.98 }\end{array}$ \\
\hline *Tom Brady & 0.83 & 0.35 & 0.96 & 0.84 \\
\hline *Drew Brees & 0.81 & 0.47 & 1.00 & 0.85 \\
\hline Otto Graham & 1.00 & 1.00 & 0.89 & 1.00 \\
\hline *Jameis Winston & 0.68 & 0.60 & 0.92 & 0.84 \\
\hline
\end{tabular}

\section{CREATING AND INTERPRETING MULTIPLE REPRESENTATIONS OF DATA}

Curriculum suggestions found in the American Statistical Society's Guidelines for Assessment and Instruction in Statistics Education (GAISE 2, 2020), IDSSP (2019) and Pro Civic Stat (Ridgeway et al.) emphasize the need to explore and interpret numerical and graphical summaries of data. In particular, given the broad scope of data students will see in their lives, these sources call for multivariable thinking and familiarity with representations involving multiple variables that interact in non-linear fashion, and change over time or across different groups being compared. An example is the level of carbon dioxide $\left(\mathrm{CO}_{2}\right)$ in the atmosphere. The data collected at the Mauna Loa Observatory in Hawaii (Our Changing Atmosphere) provide a rich opportunity to investigate one aspect of climate change. $\mathrm{CO}_{2}$ emissions, measured in parts per million (ppm), are largely caused by burning fossil fuels that keep heat, that would normally disappear into space, trapped on Earth leading to an increase in the earth's temperature. Students typically begin by constructing a variety of graphical representations (Figures 1,2,3), allowing them to see the "wave" pattern each year as well as the shift upwards (increase in level) across the years. 


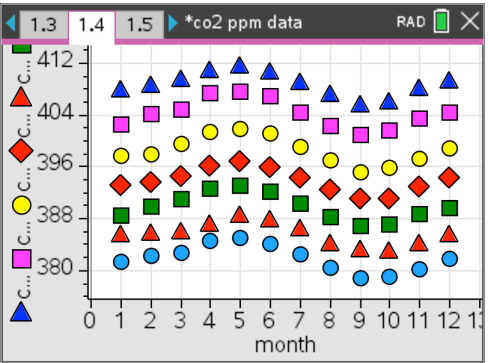

Figure 1. Mean CO2 levels '06 (bottom) to '18 (top)

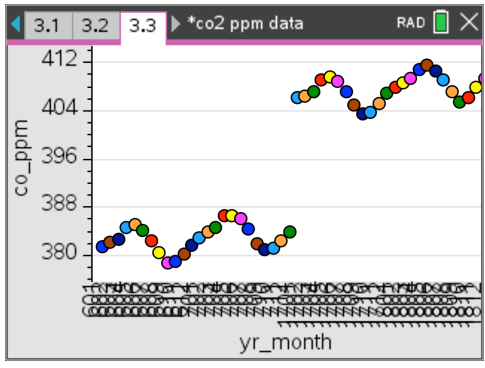

Figure 2. Mean $\mathrm{CO} 2$ levels for '06, '07, ' 17, , 18

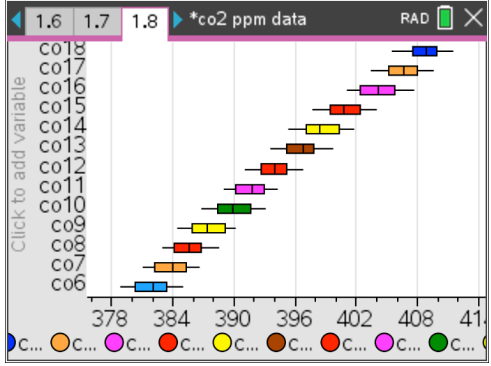

Figure 3 Box Plots mean monthly $\mathrm{CO} 2$ levels by year

Finding a model to describe the change involves thinking both about the linear trend (Figure 4) and the yearly cyclic pattern (Figure 5). Careful examination of the sine model suggests a 10-month cycle rather than a yearly cycle due to the continuing upward trend. A possible model combining both trends might be a function such as that in Figure 6 .

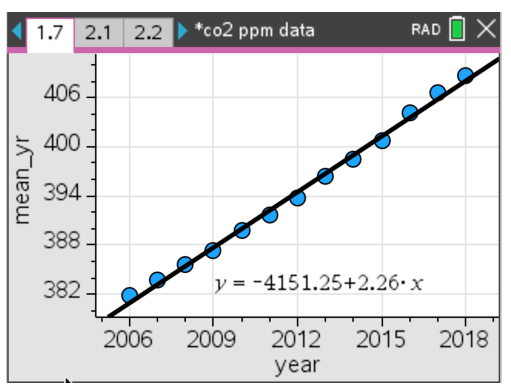

Figure 4. Using a linear model

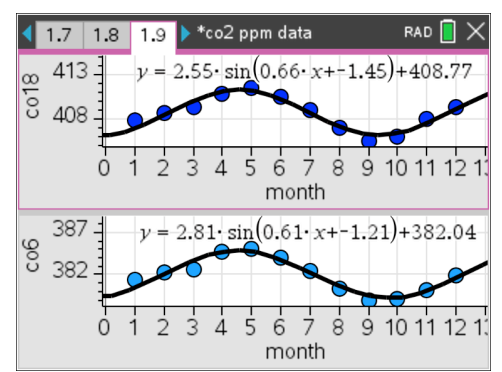

Figure 5 Using a sine function

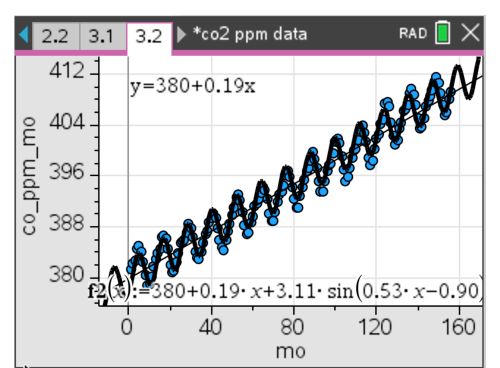

Figure 6 Combining the trends

\section{UNDERSTAND NUMBERS IN CONTEXT}

The presence of context is a defining characteristic of statistics. "Data are not just numbers, they are numbers with a context" (Moore \& Cobb, 1997, p. 801). To that end, those who analyze data should not simply be data crunchers but should interrogate the data to develop insight, make recommendations and predictions (GAISE 2, 2020). As an example, consider Figure 7, which appeared in an analysis of achievement gaps in the state of Michigan (Flores, 2014).

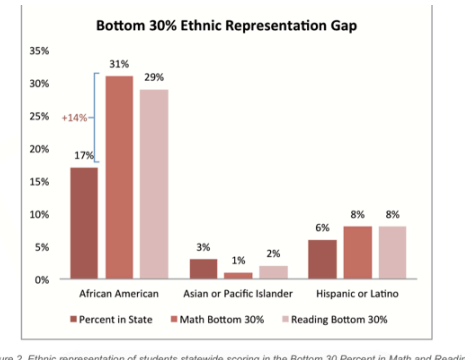

Figure 7 Achievement gaps in math and reading

While the graph contains relevant information, most people struggle with percentages presented this way (Polito, 2014). Another approach is to assume a population, say of 1,000 students, and use the percentages to find counts (i.e., the bottom $30 \%$ would be 300 students).

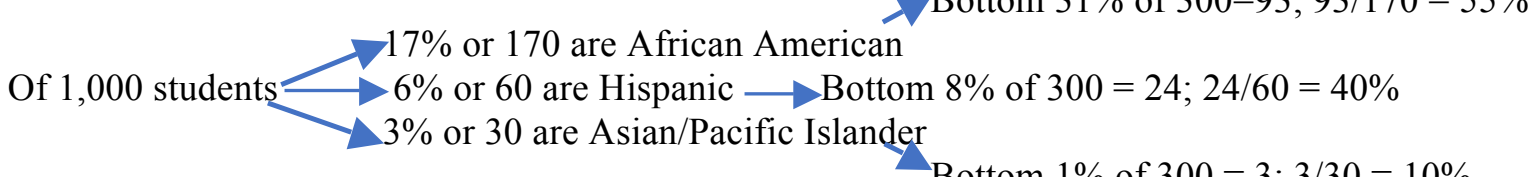

$$
\lambda \text { Bottom } 31 \% \text { of } 300=93 ; 93 / 170=55 \%
$$$$
\text { Bottom } 1 \% \text { of } 300=3 ; 3 / 30=10 \%
$$ 
This allows comparisons that seem to make the point more directly: over $1 / 2$ (55\%) of the African American students (93 out of 170) are in the bottom 30\% in math while about $40 \%$ of the Hispanic students and $10 \%$ of Asian/Pacific Islanders are in the bottom 30\%.

\section{THE CONTENT}

Many of the mathematical concepts related to quantitative literacy, such as percentages, decimals, fractions and ratios, on the surface are seen as middle grades content, appropriate for students aged 11-14 (e.g., NGA, 2010; Australian Mathematics Curriculum, 2015). Other content is typically categorized as introductory algebra: writing and solving equations and systems of equations, working with linear and exponential functions, graphing data and fitting lines to paired data. Unfortunately, these elementary ideas are rarely revisited in high school from a more sophisticated perspective. Percents and percentages are subtle and ambiguous (Schield, 2000). It is not about calculation but about the ability to apply the concept in a variety of settings (Steen, 2001). If the profit from an investment has doubled, what do you need to know to make sense of the information? Is the percent of those with a disease based on relative or absolute frequency?

Table 3 returns to the question: what topics in mathematics, statistics and data are important to be "data literate"? Based on earlier ideas about statistical literacy/quantitative thinking (Burrill, 2019) and on examples such as those described above, Table 3 offers a potential set of such topics. The list, not exhaustive, can provide a starting point for thinking about the curriculum.

Table 3 Essential concepts for informed consumers of data-based information*

\begin{tabular}{|l|l|l|}
\hline $\begin{array}{l}\text { Concepts related to } \\
\text { numeracy: students should }\end{array}$ & $\begin{array}{l}\text { Concepts related to } \\
\text { statistics: students should }\end{array}$ & $\begin{array}{l}\text { Concepts related to data: } \\
\text { students should }\end{array}$ \\
\hline $\begin{array}{l}\text { Interpret percent in contexts, } \\
\text { attending to the base and } \\
\text { connection to decimals }\end{array}$ & $\begin{array}{l}\text { Connect measures of center } \\
\text { and variability to a data } \\
\text { distribution }\end{array}$ & $\begin{array}{l}\text { Know what questions to ask } \\
\text { when given data-based } \\
\text { information in any form }\end{array}$ \\
\hline $\begin{array}{l}\text { Use and interpret fractions, } \\
\text { ratios }\end{array}$ & $\begin{array}{l}\text { Identify and interpret } \\
\text { measures of variability }\end{array}$ & $\begin{array}{l}\text { Read and interpret data in two- } \\
\text { way tables }\end{array}$ \\
\hline $\begin{array}{l}\text { Recognize probability as a } \\
\text { measure of a chance outcome }\end{array}$ & $\begin{array}{l}\text { Understand the importance of } \\
\text { random samples }\end{array}$ & $\begin{array}{l}\text { Recognize and respond to the } \\
\text { presence of outliers }\end{array}$ \\
\hline $\begin{array}{l}\text { Understand conditional } \\
\text { probability }\end{array}$ & $\begin{array}{l}\text { Understand that samples can } \\
\text { be used to predict with some } \\
\text { degree of confidence }\end{array}$ & $\begin{array}{l}\text { Make sense of and interpret } \\
\text { standard and nonstandard } \\
\text { graphs, looking at the data in } \\
\text { different ways }\end{array}$ \\
\hline $\begin{array}{l}\text { Distinguish between } \\
\text { frequency and relative } \\
\text { frequency }\end{array}$ & $\begin{array}{l}\text { Connect significance and } \\
\text { chance knowing unusual } \\
\text { events can occur by chance }\end{array}$ & $\begin{array}{l}\text { Find and interpret a model to } \\
\text { describe a relationship between } \\
\text { two or more variables }\end{array}$ \\
\hline Interpret risk/ relative risk & $\begin{array}{l}\text { Interpret margin of error in a } \\
\text { context }\end{array}$ & $\begin{array}{l}\text { Understand what correlation } \\
\text { does and does not tell you }\end{array}$ \\
\hline $\begin{array}{l}\text { Distinguish between counts } \\
\text { and percentages }\end{array}$ & $\begin{array}{l}\text { Identify possible confounding } \\
\text { factors }\end{array}$ & $\begin{array}{l}\text { Control for confounding and } \\
\text { bias }\end{array}$ \\
\hline
\end{tabular}

*Assuming that students have access to dynamic interactive software or handhelds

\section{CONCLUSION}

This paper proposes rethinking the curriculum based on a synthesis of recommendations for statistical literacy, quantitative reasoning and data science and suggests a framework that integrates these ideas. The paper identifies foundational concepts necessary to enable students to engage with real data sets in the learning process and describes potential curricular elements that are important for all students from the three perspectives.

Much of this thinking has been around for decades; data science provides an opportunity to revisit these ideas from a new perspective. The proposed framework, the examples and the list of potential essential elements collectively suggest a possible vision of what is needed in curricula where 
students use and make sense of data. But making this vision a reality is challenging: lack of curricula that address statistical literacy and quantitative thinking: teacher preparation programs that do not include courses focused on making sense of mathematics and statistics, universities courses taught by instructors with limited understanding of the subjects, assessments that ignore quantitative reasoning and statistical literacy, and lack of funding for the professional development of teachers to enable them to teach in accordance with the vision. The increasing importance of data science can be the motivation for the system to begin to address these challenges.

\section{REFERENCES}

Australian Bureau of Statistics. (2009). What is statistical literacy and why is it important to be statistically literate? 1307.6 - Tasmanian State and Regional Indicators.

Australian Mathematics Curriculum (2015). https://www.australiancurriculum.edu.au/f-10curriculum/mathematics/

Burrill, G. (2018). Student work from STT 250: Statistics and Probability for Elementary Teachers. Michigan State University.

Burrill, G. (2019). Statistical literacy and quantitative reasoning. In A. Rogerson, \& J. Morska (Eds.) Proceedings of the 15th International Conference, Theory and Practice - an Interface or a Great Divide? Maynooth University, Kildare, Ireland.

DeVeaux, R. (2019). Data science for all. Keynote presentation. International Association for Statistical Education 2019 Satellite Conference, Kuala Lumpur, Malaysia

Flores, S. (2014). Quantifying the achievement gap: Baseline characteristics of African-American student achievement in Michigan. Michigan Department of Education

Gal, I. (Ed.). (2000). Adult numeracy development: Theory, research, practice. Cresskill, NJ: Hampton Press.

Gal, I. (2002). Statistical literacy: Meanings, components, responsibilities. In J. Garfield, \& D. BenZvi (Eds.). The challenge of developing statistical literacy, reasoning and thinking (pp. 4778). Dordrecht: Kluwer.

Garber, A. M. (2019). Data science: What the educated citizen needs to know. Harvard Data Science Review, 1(1).

Guidelines for assessment and instruction in statistics education 2: PreK-12 report (GAISE 2) (2020). http://www.amstat.org/education/gaise.

International Data Science School Project (IDSSP). Curriculum team, Curriculum frameworks for introductory data science, http://idssp.org/files/IDSSP_Frameworks_1.0.pdf.

Lovett, J., \& Lee, H. (2017). New standards require teaching more statistics: Are preservice secondary mathematics teachers ready? Journal of Teacher Education, 68(3) 299-311.

Moore, D. and Cobb, G. (1997). Mathematics, statistics, and teaching. American Mathematical Monthly, 104, 801-823.

National Council of Teachers of Mathematics. (2018). Catalyzing change in high school mathematics: Initiating critical conversations. Reston VA: The Council.

National Governors Association Center for Best Practices \& Council of Chief State School Officers (NGA). (2010). Common core state standards for mathematics. Washington, DC

Our Changing Atmosphere www.exploratorium.edu/snacks/our-changing-atmosphere

Polito, Jessica (2014). The language of comparisons: Communicating about percentages, Numeracy, $7(1)$.

Ridgway, R., Nicholson, J., Gal, I., \& Ridgway, J. Understanding statistics about society: A brief framework of knowledge and skills needed to engage with Civic Statistics. (Accessed May 10, 2020). https://iase-web.org/islp/pcs/documents/Conceptual_framework_brief.pdf? 1543033023

Schield, M. (2000). Statistical literacy: Difficulties in describing and comparing rates and percentages. Presentation at the American Statistical Association Joint Statistical Meeting.

Steen, L.A., (1997). Why numbers count: Quantitative literacy for tomorrow's America. College Entrance Examination Board: New York, New York.

Steen, L. A., (Ed.) (2001). Mathematics and democracy: The case for quantitative literacy. The National Council on Education and the Disciplines. Princeton NJ: The Woodrow Wilson National Fellowship Foundation. 